\title{
Case Report: Signal Drop on MRA Imaging of the Internal Carotid Artery after Neuroform Stent Placement
}

\author{
Aditya S. Pandey MD \\ Thomas Jefferson University \\ Meryl A. Severson III MD \\ Thomas Jefferson University \\ Robert H. Rosenwasser MD \\ Thomas Jefferson University
}

Follow this and additional works at: https://jdc.jefferson.edu/jhnj

Part of the Neurology Commons

Let us know how access to this document benefits you

\section{Recommended Citation}

Pandey MD, Aditya S.; Severson III MD, Meryl A.; and Rosenwasser MD, Robert H. (2008) "Case Report: Signal Drop on MRA Imaging of the Internal Carotid Artery after Neuroform Stent Placement," JHN Journal: Vol. 4 : Iss. 1 , Article 1.

DOI: https://doi.org/10.29046/JHNJ.004.1.004

Available at: https://jdc.jefferson.edu/jhnj/vol4/iss1/1

This Article is brought to you for free and open access by the Jefferson Digital Commons. The Jefferson Digital Commons is a service of Thomas Jefferson University's Center for Teaching and Learning (CTL). The Commons is a showcase for Jefferson books and journals, peer-reviewed scholarly publications, unique historical collections from the University archives, and teaching tools. The Jefferson Digital Commons allows researchers and interested readers anywhere in the world to learn about and keep up to date with Jefferson scholarship. This article has been accepted for inclusion in JHN Journal by an authorized administrator of the Jefferson Digital Commons. For more information, please contact: JeffersonDigitalCommons@jefferson.edu. 


\section{Case Report: Signal Drop on MRA Imaging of the Internal Carotid Artery after Neuroform Stent Placement}

\author{
Aditya S. Pandey, MD, Meryl Severson, MD, Robert Rosenwasser, MD \\ Department of Neurological Surgery, Thomas Jefferson University Hospital, Philadelphia, PA
}

\section{Introduction}

Magnetic resonance angiography (MRA) is an important tool in evaluating the patency of vessels which have previously been stented. Neuroform stents (Boston Scientific, Natick, MA, U.S.A.) are utilized to provide a scaffold across the neck of an aneurysm. These stents are synthesized from Nitinol (nickel and titanium) and thus cause minimal distortion upon imaging with MRA. Patients who have undergone Neuroform stent assisted coiling of aneurysms are routinely followed with MRA to delineate stenosis of the stented segment of vessel as well as recurrence of the aneurysms. While numerous reports show that Neuroform stents do not lead to MRA imaging artifact, we report of a case where the utilization of the Neuroform stent led to a signal drop out at the site of the stent upon evaluation with MRA and thus led to further invasive radiological procedures.

\section{Materials and Methods}

This study is a case report identifying Magnetic resonance imaging artifact associated with the use of Neuroform stents. Data was collected from the patient's chart, operative report, and imaging studies.

\section{Case Report}

The patient presented in this report is a 55 year old right handed female who underwent screening MRA of the head due to a family history of subarachnoid hemorrhage. This revealed a $5 \mathrm{~mm}$ left carotid wall aneurysm. Subsequently, cerebral angiography revealed a broad based $6 \mathrm{~mm}$ by $4 \mathrm{~mm}$ left posterior carotid wall aneurysm (Figure 1). The angioarchitecture of the aneurysm made it necessary to place a stent in order to prevent coil prolapse into the parent vessel.

Due to technical difficulty associated with the tortuousity of the vessel, a Neuroform-3 stent was prematurely deployed into the lacerum portion of the left internal carotid artery (ICA). However, another neuroform-3 stent was able to be placed across the neck of the posterior carotid wall aneurysm. Postoperatively, the patient remained neurologically intact and was maintained on plavix therapy to prevent thromboembolic events. We allowed the stent to adhere to the vessel over a period of eight weeks at which time the patient underwent coil embolization of the aneurysm without any complications (Figure 2).

Four weeks post coiling, the patient presented to the emergency room complaining of right sided numbness and tingling. A computed tomographic (CT) scan of the head was unrevealing of any pathology. An MRI/A of the neck and head was performed to delineate whether a carotid dissection with associated thromboembolic event was the causation for the patient's symptoms (Figure 3). This revealed a change in the caliber of the left ICA at the level of the petrous carotid. While certainly this could represent susceptibility artifact from the deployed stent, no such cases have been reported in the English literature. Thus the above mentioned imaging results led to the patient being admitted to the hospital and subsequent prophylactic anticoagulation. A CTA of the head was performed to better understand the exact location and length of the dissected segment of vessel (Figure 4). Due to the surrounding bone associated with the petrous carotid artery, the CTA was not revealing in delineating whether the MRA findings represented artifact or actual vascular dissection. Thus it was essential to perform cerebral angiography which revealed no evidence of dissection or recurrence of the previously coiled aneurysm (Figure 5).

\section{Discussion}

Use of self expanding Nitinol stents has revolutionized the treatment of intracranial aneurysms as well as intracranial atherosclerotic disease. MRI/A have been shown to be of great value in evaluating restenosis of a treated vessel or recanalization of treated aneurysms where these stents have been utilized. A multitude of reports in the English literature have revealed that MRI/A creates minimal

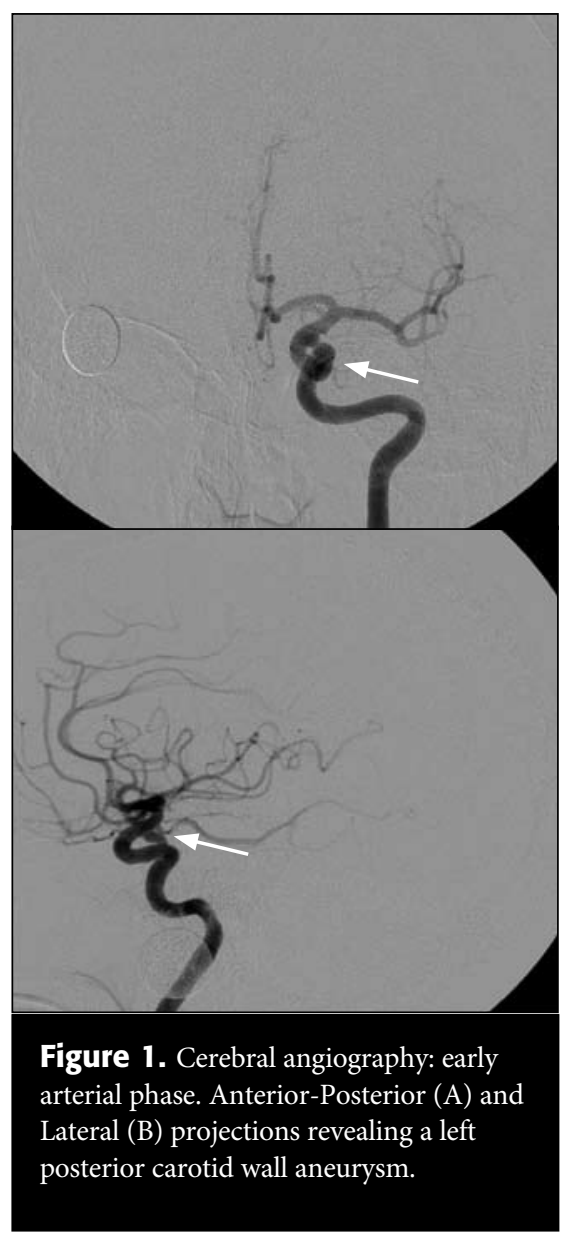

artifact when imaging vessels with these stents. In fact, there are no reports of MRA associated signal drop out from imaging of vessels which have been stented with Neuroform stents.

Our case report exemplifies that MRA imaging can indeed create a signal drop out at the site of Neuroform stent placement thus creating a false image of possible dissection of the vessel. Such an artifact can lead to further treatments and imaging which not only increase the cost burden to society but also can increase the morbidity to the patient. While we did perform a computed tomographic angiography (CTA) of the head, it was of no value as the artifact from the petrous bone prevented a clear delineation of whether a dissection existed or not. 


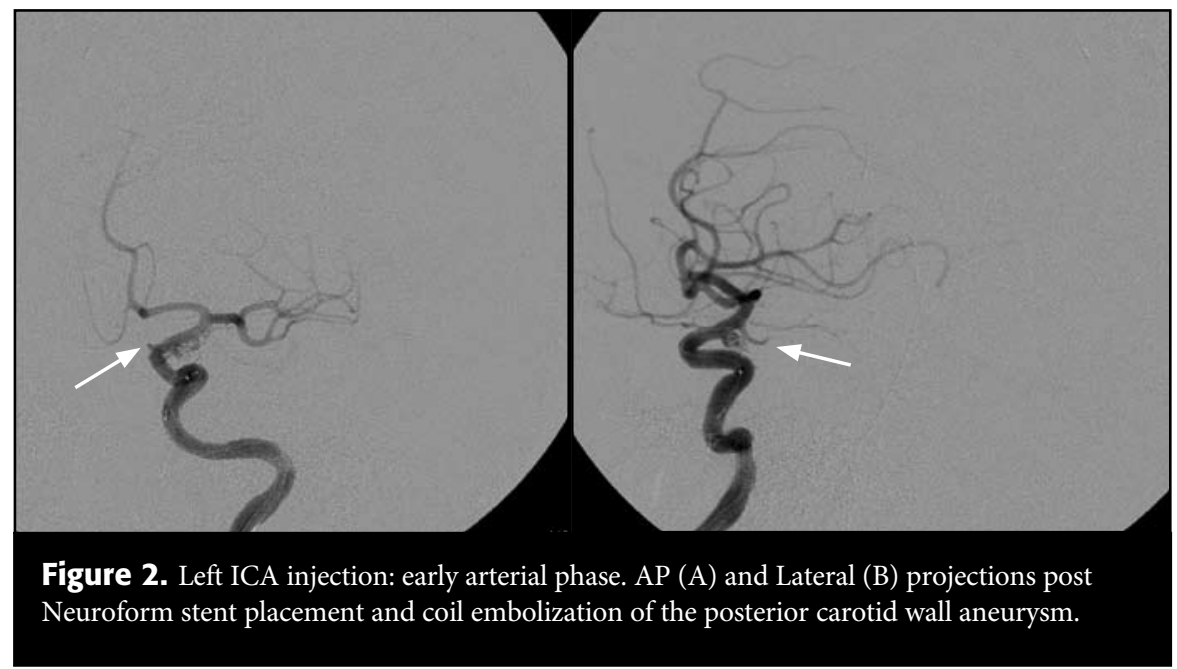

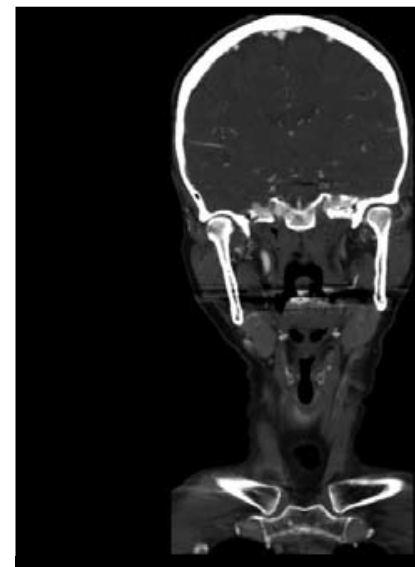

Figure 4. Computed tomographic angiography (CTA) of the head revealing the left petrous ICA not well visualized due to artifact created from the petrous bone.

Neuroform- 3 stents can create MRI associated artifact/signal drop out and such this should be taken into account when imaging vessels which house such stents. While MRA with gadolinium or CTA head can better visualize the pathology, cerebral angiography remains the gold standard in evaluating vessels which have undergone stenting.

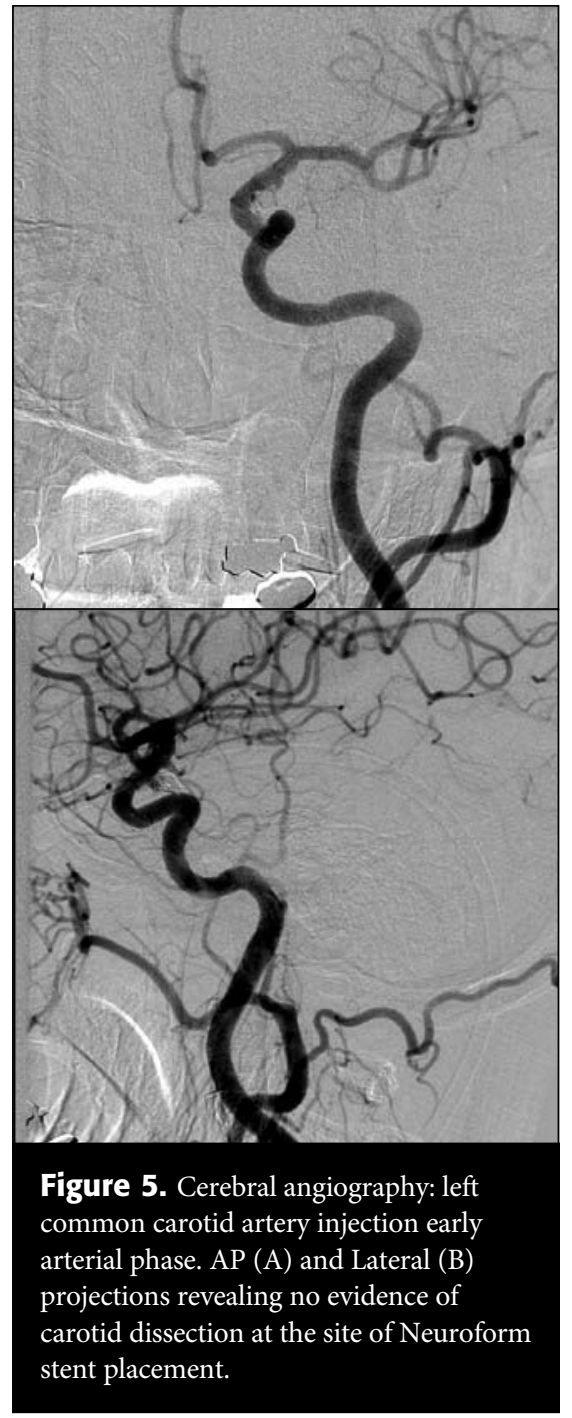

Figure 3. Magnetic Resonance Angiography (MRA) of the head revealing a left petro us carotid artery dissection which was later proved to be signal drop out from the presence of a Neuroform stent. 